\title{
ALFABETIZAÇÃO E OS MULTILETRAMENTOS: UMA PROPOSTA DE FORMAÇÃO DOCENTE EM PRÁTICAS DE LETRAMENTO DIGITAL
}

\author{
Rosângela Costa Soares ${ }^{1}$ \\ https://orcid.org/0000-0003-3194-1949 \\ Verônica Domingues Almeida² \\ https://orcid.org/0000-0001-5232-3838
}

RESUMO: O presente trabalho apresenta o percurso teórico-investigativo que originou o Projeto de Intervenção intitulado "Alfabetização e os multiletramentos: uma proposta de formação docente em práticas de letramento digital". Inscrito no campo de debates da formação de professores alfabetizadores em uma perspectiva de multiletramentos, o Projeto de Intervenção foi subsidiado por uma pesquisa exploratória, de cunho qualitativo que investigou, através da revisão de literatura e da aplicação de um questionário on-line, como professores da Rede Municipal de Educação de Lauro de Freitas-Ba concebem práticas de alfabetização aliadas aos multiletramentos e como atuam no que tange ao letramento digital. A partir dos resultados, foi elaborada uma proposta interventiva de caráter colaborativo e concebida como pesquisa-ação em rede, tendo o blog como ambiente virtual de aprendizagem e portfólio digital. A proposta visa a ampliar as práticas de alfabetização para o letramento digital na indicada rede educativa, através do acompanhamento da organização do trabalho pedagógico, realizado por meio da elaboração de recursos educacionais e da construção e execução de uma rotina didática, com sequências e projetos pedagógicos em práticas letradas digitais. Espera-se que a intervenção contribua com a reconfiguração de processos de ensinar e de aprender na contemporaneidade, ressignificando saberes e práticas docentes e potencializando o letramento digital nos processos de alfabetização.

PALAVRAS-CHAVE: alfabetização, formação docente, letramento digital, multiletramentos.

\footnotetext{
${ }^{1}$ Mestrado em Gestão e Tecnologias Aplicadas à Educação. Professora da Rede Municipal de Educação de Lauro de Freitas, Bahia, Brasil. r.angela78@gmail.com

${ }^{2}$ Doutorado em Educação. Professora Adjunta da Faculdade de Educação. Universidade Federal da Bahia Salvador, Bahia, Brasil.veedomingues@gmail.com
} 


\section{LITERACY AND MULTI-TRAINING: A TRAINING TEACHER PROPOSAL ON DIGITAL LITERACY PRACTICES}

ABSTRACT: This work presents the theoretical-investigative pathway that originates the entitled project: "Literacy and Multi-training: a training teacher proposal on digital literacy practices". Enrolled in the field of debates on the training of literacy teachers in a multi-training perspective, the Intervention Project was subsidized by an exploratory, qualitative research that investigated, through the literature review and the application of an online questionnaire, how teachers from the Municipal Education Network of Lauro de Freitas-BA, conceive the literacy practices linked to multi-training, and how they operate and how they act regarding to digital literacy. Based on the results, a collaborative intervention proposal was developed and conceived as a network research-action, with the blog as a virtual learning environment and digital portfolio. The proposal aims to expand literacy practices for digital literacy in these indicated educational network, by monitoring the organization of pedagogical work, through the elaboration of educational resources and the construction and execution of a didactic routine, with sequences and pedagogical projects in digital literacy practices. Is expected that the research contributes to the reconfiguration of teaching and learning processes in the contemporary world, giving new meaning to teaching knowledge and practices and enhancing digital literacy in literacy processes.

KEYWORDS: literacy, teacher training, digital literacy, multi-training.

\section{ALFABETIZACIÓN Y LOS MULTILETRAMIENTOS: UNA PROPUESTA DE FORMACIÓN DOCENTE EN PRÁCTICAS DE LETRAMIENTO DIGITAL}

RESUMEN: El presente trabajo presenta el recorrido teórico-investigativo que originó el proyecto de intervención titulado: "Alfabetización y los multiletramientos: una propuesta de formación docente en prácticas de letramiento digital. Inscrito en el campo de debates de la formación de profesores alfabetizadores en una perspectiva de multiletramientos, el proyecto de intervención fue apoyado por una investigación exploratoria, de tipo cualitativo que investigó, a través de la revisión de literatura y de la aplicación de un cuestionario on-line, cómo profesores de la Red Municipal de Educación de Lauro de Freitras-BA, conciben las prácticas de alfabetización unidas a los multiletramientos y cómo actúan en lo que respecta al letramiento digital. A partir de los resultados, fue elaborada una propuesta de intervención de carácter colaborativo y concebida como investigación-acción en red, teniendo el blog como ambiente virtual de aprendizaje y portafolio digital. La propuesta encara ampliar las prácticas de alfabetización para el letramiento digital en la red educativa mencionada, por medio del acompañamiento de la organización del trabajo pedagógico; de la elaboración 
de recursos educativos y de la construcción y ejecución de una rutina didáctica, con secuencias y proyectos pedagógicos, en prácticas digitales letradas. Se espera que la intervención contribuya con la reconfiguración de procesos de enseñar y aprender en la contemporaneidad, resignificando saberes y prácticas docentes y potencializando el letramiento digital en los procesos de alfabetización.

PALABRAS CLAVE: alfabetización, formación docente, letramiento digital, Multiletramientos.

\section{Introdução}

Este artigo apresenta o percurso teórico-investigativo que originou o Projeto de Intervenção (PI) intitulado "Alfabetização e os multiletramentos: uma proposta de formação docente em práticas de letramento digital" elaborado com o objetivo de potencializar a formação docente para a ampliação das práticas de multiletramentos em classes de alfabetização de escolas da Rede Municipal de Educação de Lauro de Freitas-Bahia. Inscrito no campo de debates da formação de professores alfabetizadores em uma perspectiva de multiletramentos, o PI seguiu o que colocam Almeida e Sá (2017), em relação ao salto da ideia de intervenção como projeção e aplicação, para a ideia de intervenção como investigação e implicação, compreendendo que para isso é fundamental que a proposta

apresente uma relação intrínseca entre o objeto de investigação do pesquisador e a realidade escolar, que seja construída na interação com os pares da rede de educação e que tenha em seu cerne a concepção de abertura, como uma intervenção articuladora (ALMEIDA; SÁ, 2017, p. 10).

A temática de pesquisa e de intervenção tem relação direta com a necessidade de qualificação docente no que tange a diversificação de perspectivas da formação para o campo da alfabetização. Os baixos níveis de proficiência em Língua Portuguesa, Matemática e Ciências, apresentados pelo Programa Internacional de Avaliação de Estudantes (OCDE, 2019) ${ }^{3}$ e pelo Sistema de Avaliação da Educação Básica (BRASIL, 2018) , além das informações divulgadas

\footnotetext{
${ }^{3}$ Para maiores informações, consulte: http://portal.inep.gov.br/web/guest/acoes-internacionais/pisa/ resultados

${ }^{4}$ Informações detalhadas podem ser acessadas em: http://portal.inep.gov.br/web/guest/educacao-basica/ saeb/resultados
} 
pelo relatório da Avaliação Nacional da Alfabetização (BRASIL, 2016) ${ }^{5}$ que, entre outros dados relevantes, mostra que a Região Nordeste possui apenas $52,1 \%$ dos professores alfabetizadores com formação adequada, demonstram a urgência das redes de educação se dedicarem a gestar possibilidades de superação de tais problemáticas. Ademais, tal contexto atrelado às novas configurações sociais, que incluem a vasta influência das tecnologias digitais nos comportamentos humanos e a existência de barreiras para incursão destas tecnologias na escola (SANTOS, 2015), indicam a necessidade de buscarmos ressignificar o fazer pedagógico no caminho da criação de novas formas de construir os conhecimentos.

Nesse horizonte, é importante considerar que os multiletramentos compõem práticas construtivas e efetivas importantes para os processos de aquisição da leitura e da escrita, a fim de que a alfabetização não seja uma aprendizagem meramente mecânica e desvinculada da formação crítica e ética fundamental para a sociedade. Por outro lado, diante do cenário exposto, nos questionamos a respeito da qualificação docente necessária para abarcar essas novas demandas do escopo social: Estariam os professores preparados para práticas alfabetizadoras situadas na perspectiva dos multiletramentos? E em relação ao letramento digital, os docentes possuem os elementos práxicos necessários para instituir seu trabalho em sala de aula por essa concepção? Evitando respostas absolutistas, mas levando em consideração a realidade da rede de educação em que o PI foi construído, podemos afirmar que existe um distanciamento entre as práticas alfabetizadoras vigentes e as perspectivas de multiletramentos, assim como, de letramento digital.

Dessa forma, buscamos intervir nessa realidade através da construção de uma proposta de formação docente em alfabetização, situada na perspectiva dos multiletramentos e voltada para práticas letradas digitais, tendo o blog como ambiente virtual de aprendizagem e portfólio digital. A elaboração da proposta interventiva foi subsidiada por informações advindas de uma pesquisa exploratória, de cunho qualitativo, que utilizou como instrumento de coleta de dados um questionário on-line, distribuído, no período de 10 de julho a 10 de agosto de 2019, para 187 professores das classes do ciclo de alfabetização 1으, 2 ㅇ e 3ㅇaㅇ an do ensino fundamental, participantes do Programa Nacional Mais Alfabetização (PMALFA), da Rede Municipal de Educação de Lauro de Freitas (SEMED), Bahia. A pesquisa teve como objetivo compreender como os professores se situam na perspectiva dos multiletramentos e identificar o nível de

${ }^{5}$ É possível acessar o relatório na íntegra através do site: http://portal.inep.gov.br/informacao-da-publicacao/-/asset_publisher/6JYIsGMAMkW1/document/id/1510096 
fluência e as competências digitais dos mesmos, levantando suas necessidades formativas para o desenvolvimento do PMALFA e ofertando subsídios para a SEMED na formulação de uma agenda formativa em educação e tecnologias digitais para os docentes.

Para fundamentar o PI buscamos inspirações nos estudos sobre pesquisa-ação de Tripp (2005) e de formação em rede de Almeida (2010) a fim de criar uma proposta que percebesse os docentes como atores e autores do processo formativo e fosse delineada em uma perspectiva de investigação e ação em rede. Vale apontar, também, que o esteio que fundamentou o estudo e a análise dos dados esteve pautado, ainda, nos escritos de Alarcão (2010), Bonilla (2002; 2005; 2009), Freitas (2009), Lemos (2010), Soares (1998; 2002), Rojo e Moura (2012), entre outros.

Acreditamos que diante dos desafios contemporâneos o campo educacional precisa investir na construção de novas perspectivas de atuação, envolvendo a gestão das redes de ensino, a equipe gestora e técnica escolar e os docentes, na reconfiguração de práticas pedagógicas, a fim de, não apenas, acompanhar o desenvolvimento integral dos estudantes, mas também, ampliar possibilidades aperfeiçoamento profissional para além das ações tradicionalmente assentadas na esfera educativa. Assim, é esta a nossa proposta neste texto: apresentar os percursos teóricos-investigativos que geraram um Projeto de Intervenção no campo da formação de professores alfabetizadores, com vistas a discutir a perspectiva dos multiletramentos, mais especificamente, o letramento digital na práxis educativa. Para tanto, contextualizaremos, inicialmente, as relações entre a formação docente e a cultura digital, em seguida, abordaremos o ensino da alfabetização e os multiletramentos, dando ênfase ao letramento digital, e, por fim, apresentaremos as etapas do plano de formação, que consiste na proposta de intervenção propriamente dita.

\section{Formação docente e a cultura digital}

As constantes mudanças sociais na forma de compreender e de habitar o mundo na contemporaneidade impulsionadas pelos recursos digitais, como "[...] uma nova forma de cultura" (LÉVY, 2010, p. 11), exigem um movimento contínuo de ressignificação do modo como pensamos o conhecimento, as relações com os outros e a própria sociedade. Desse modo, a cultura digital vem alterando as relações sociais e afetando em maior ou menor escala todos os aspectos da ação humana, pois "[...] inclui reorganizações da língua escrita e falada, das ideias, crenças, costumes, códigos, instituições, ferramentas, mé- 
todos de trabalho, arte, religião, ciência, enfim, todas as esferas da atividade humana (PRETTO; ASSIS, 2010, p. 78).

Diante desta conjuntura, a escola, instituição secular responsável por potencializar as relações humanas, a produção do conhecimento e a aprendizagem, passa por transformações que, cada vez mais, exigem que ela se desloque de uma posição meramente instituída e se coloque, também, como dimensão instituinte desse cenário. Assim, a escola

[...] ao mesmo tempo em que sofre essas influências, pode também influir nestes tempos e espaços, à medida que for se abrindo para a ressignificação das concepções mecanicistas sobre o pensamento, o conhecimento e a comunicação que impregnam o sistema educacional e todas as outras instituições sociais e políticas [...]. (BONILLA, 2005, p. 71).

Nessa teia de novas configurações educacionais, ser professor "[...] exige competências de acesso, avaliação e gestão da informação oferecida" (ALARCÃO, 2010, p. 12) e, justamente, por essa razão "as escolas são lugares onde as novas competências devem ser adquiridas ou reconhecidas e desenvolvidas" (ibidem, p. 12). A aprendizagem vinculada aos contextos digitalizados, como cerne da sociedade contemporânea, evidenciou ainda mais a função da escola de favorecer a construção dos conhecimentos de modo diversificado e de potencializar competências e habilidades que favoreçam a esse fim.

Um campo que recebe diretamente os impactos dessa nova configuração social e educativa é o da formação docente. Diante desse panorama, os educadores precisam acompanhar as novas demandas colocadas à atividade educacional, afinal, ser professor, nestes tempos, necessita ser "[...] um incansável pesquisador. Um profissional que se reinventa a cada dia, que aceita os desafios e a imprevisibilidade da época para se aprimorar cada vez mais" (KENSKI, 2003, p. 90), devem, portanto, buscar investigar a própria prática com a finalidade de melhorá-la (TRIPP, 2005). Nesse contexto, a formação docente deve acompanhar os profissionais em tais atualizações, não se configurando em ações estanques, mas se constituindo como processo continuado de reflexão-pesquisa-ação, inerente ao próprio exercício da docência. Desse modo, é preciso que a formação docente deixe de ser compreendida como capacitação, curso ou absorção de informações, de modo isolado, e passe a ser delineada em uma perspectiva de produção colaborativa de conhecimentos, favorecendo a construção de redes formativas, diferindo, portanto, da concepção sistemática que limita a formação a uma meta estanque (ALMEIDA, 2010). 
Compreender a formação docente, especialmente em um contexto de cultura digital, implica em um deslocamento da concepção de formação como fim e processo individual para a ideia de formação como contínuo colaborativo, em uma perspectiva de rede. Redes de formação são capazes de aproximar sujeitos e instituições, de forma colaborativa, em torno de objetivos comuns. Por terem essa característica interativa, as redes se estabelecem de modo horizontalizado, interconectado e através de meios de atuação não hierárquicos ou dominantes. A formação proposta em uma perspectiva contínua, de rede investigativa e colaborativa, compreende os professores como atores e autores de seus processos formativos.

Atores enquanto sujeitos que comunicam, executam e partilham ações, percebem e interpretam o mundo, a linguagem e os atos próprios de seu contexto, compartiIhando uma compreensão comum de suas trocas, o que permite a apreensão da significação dos acontecimentos. Autores enquanto sujeitos construtores, produtores e transformadores de seus mundos, das regras que os engendram e governam seu julgamento (BONILLA, 2002, p. 19 , grifos da autora).

O efervescer da sociedade contemporânea em uma cultura das redes não pode ser dissociado da formação docente, pois, mais do que nunca, os sujeitos além de acessarem informações passaram a contribuir com diversas esferas sociais através, também, da produção de conteúdo. Por isso, é importante evidenciarmos uma concepção de formação em que os professores sejam vistos como atores e autores de seus processos formativos, indo além da aquisição passiva e da reprodução de informações já postas pela sociedade, a partir de uma postura reflexiva, criativa, investigativa e colaborativa. Acreditamos que as características da cultura digital contemporânea oportunizam o fortalecimento dos processos formativos pautados na investigação da prática educacional porque propiciam as condições necessárias para que os professores assumam a própria realidade escolar como um objeto de pesquisa, de reflexão e de análise (NÓVOA, 2001). Desse modo, é importante evidenciarmos a formação de professores em uma perspectiva de pesquisa, a partir de redes colaborativas, por estas favorecerem as dimensões instituídas e instituintes da escola e compreenderem os professores não apenas como atores, mas também como autores e produtores de saberes.

Almeida (2010) destaca a formação docente em uma perspectiva de rede a partir de três dimensões: Formação para a rede, na rede e em rede. 
Para a autora, a formação para a rede não se limita a apreender o manuseio dos aparatos tecnológicos digitais, mas envolve também a compreensão, por parte do professor, de que a web é uma produtora e retroalimentadora de conhecimentos, inclusive, de sua autoria. Já a formação na rede leva em conta a participação em esferas formativas, tendo o letramento digital como um suporte importante para que aconteça. Pode ser desenvolvida tanto através de EAD, listas de discussão, chats ou, como pesquisou Adriane Halmann (2006), através de blogs. Já a formação em rede ocorre com a participação do docente em comunidades que possuem a mesma necessidade formativa e que tenham cunho colaborativo. Vale apontar que essas dimensões não podem ser consideradas como passos organizados hierarquicamente, já que a formação por este viés [...] é contínua e livre, não há limite de tempo ou espaço: o que rege é o desejo de construir conhecimentos, difundi-los, utilizá-los. O interesse é em formar-se escolhendo os trajetos - digitais ou não - na complexidade, em rede (ALMEIDA, 2010, p. 46).

Levando em conta essas concepções de formação impregnadas pela cultura digital é que o Projeto de Intervenção foi proposto. A ideia é poder contribuir com os processos formativos de docentes em uma perspectiva investigativa e colaborativa, tendo o letramento digital como um objetivo de dupla entrada, no qual, ao formar-se neste âmbito, o professor poderá potencializar, também, o letramento digital nos processos de alfabetização de seus alunos. Acreditamos que implicados em uma postura de investigação e ação (TRIPP, 2005), voltada para a rede, na rede e em rede (ALMEIDA, 2010), os educadores poderão promover alterações no escopo educativo atual tendo o letramento digital como um horizonte mais próximo em suas práticas alfabetizadoras.

\section{Alfabetização e os multiletramentos}

Na busca pela compreensão sobre a formação docente para a alfabetização e do letramento, em uma perspectiva digital, é que sentimos a necessidade de discutir a respeito desses termos. Maria Teresa Freitas (2009), analisando a cibercultura e a formação de professores, sublinha que o ponto central do trabalho docente é a aprendizagem e seus processos. Para ela "[...] as novas práticas de leitura-escrita construídas na internet estão apontando para a necessidade de mudanças dessas práticas nos espaços educacionais" (FREITAS, 2009, p. 60). A contribuição da referida autora mostra que conforme surgem novos tipos de práticas letradas, novos processos de ensino devem ser desenvolvidos e é neste escopo que se situa a discussão sobre alfabetização, 
multiletramento e letramento digital.

Para tratar de multiletramento e letramento digital voltados para professores alfabetizadores, ou seja, responsáveis pela etapa formal de ensino destinada à alfabetização, é importante compreender onde se situam tais conceitos em termos epistemológicos. Por alfabetização se compreende o processo pelo qual uma pessoa se torna capaz de codificar e decodificar os fonemas em grafemas ou letras, estabelecendo relações grafofônicas entre esses dois sistemas de materialização da língua escrita (BRASIL, 2012). O letramento e suas variações, como é o caso do letramento digital, compreende o uso social da leitura e da escrita em diversos formatos e portadores, como textos impressos, multimodais, hipertextuais e hipermidiáticos. Desse modo, apesar da alfabetização estar relacionada à apropriação do sistema notacional e o letramento "[...] aos usos e reflexões da escrita em atividades de leitura e escrita de textos, em contextos diversos" (ALBUQUERQUE; MORAIS; FERREIRO, 2010, 18) são processos indissociáveis (SOARES, 1998). Por conseguinte, seguindo a este princípio, a escola tem um papel fundamental em alfabetizar e letrar. Como bem propôs, Magda Soares (1998, p. 47) “[...] o ideal seria alfabetizar letrando, ou seja: ensinar a ler e escrever no contexto das práticas sociais da leitura e da escrita, de modo que o indivíduo se tornasse, ao mesmo tempo, alfabetizado e letrado".

Levando em conta que letramento é o "[...] estado ou condição de indivíduos ou grupos sociais de sociedades letradas que exercem efetivamente as práticas sociais de leitura e de escrita e participam competentemente de eventos de letramento" (SOARES, 2002, p. 145), acreditamos que as práticas a partir de tecnologias de leitura e de escrita, desenvolvidas no percurso histórico, demonstram a evolução dos formatos de letramentos, tal como é o caso da introdução das tecnologias digitais. Dessa forma, nos referimos a letramento digital como "[...] um certo estado ou condição que adquirem os que se apropriam da nova tecnologia digital e exercem práticas de leitura e de escrita na tela, diferente do estado ou condição - do letramento - dos que exercem práticas de leitura e de escrita no papel" (SOARES, 2002, p. 146).

Em relação os aspectos pedagógicos das práticas letradas digitais na escola, Rojo e Moura (2012) inauguram no Brasil a discussão sobre a necessidade de sistematização do ensino baseado nos multiletramentos, especialmente, sobre o letramento digital. Fundamentados no manifesto A Pedagogy of Multiliteracies - Designing Social Futures ${ }^{6}$, desenvolvido pelo Grupo Nova Londres (GNL), os autores caracterizam os multiletramentos como o resultado

"Traduzido como: "Uma pedagogia dos multiletramentos - desenhando futuros sociais". 
da multiplicidade cultural das populações e da diversidade de textos semióticos circulantes, sobretudo nas áreas urbanas (ROJO; MOURA 2012). A abordagem metodológica defendida por Rojo e Moura (2012) está sistematizada em quatro princípios para o ensino da língua falada e escrita. O primeiro princípio, usuário funcional, refere-se à técnica e ao conhecimento prático que o estudante deve ter sobre as variadas formas letradas de comunicação e informação produzidas e circulantes na sociedade. O segundo, denominado criador de sentidos, baseia-se na forma como diferentes tipos de textos e de tecnologias operam. Já o princípio transformador trata da modificação, recriação e aplicação de outros designers no que foi aprendido e o último princípio, analista crítico, versa sobre o entendimento de que a produção estudantil deve ser resultado de seleção prévia e criteriosa das fontes.

A literatura sobre alfabetização e letramento aliada ao debate sobre os multiletramentos, mais especificamente, o letramento digital, nos revela que pautar essas perspectivas em sala de aula demanda um olhar complexo sobre a realidade. Ademais, tais disposições se colocam como um desafio no contexto da educação pública brasileira, seja por representar um bem cultural privilegiado e, portanto, de difícil acesso a boa parte da população, especialmente os estudantes das camadas menos favorecidas, seja por buscar romper com o modelo de educação bancária (FREIRE, 2015), no qual o letramento e suas variações são serviam de horizonte formativo. Nesse panorama dual, nos cabe questionar como é possível potencializar o ensino da alfabetização na perspectiva do letramento digital e, no âmbito maior da proposta de intervenção, como a formação docente se relaciona com este questionamento.

Atualmente, o Brasil tem como documento orientador do conjunto de aprendizagens essenciais a ser desenvolvido nas etapas e modalidades da Educação Básica, a Base Nacional Comum Curricular (BNCC). Este documento visa à implantação de dez competências gerais da Educação Básica, que atendem as dimensões cognitivas, sociais e pessoais dos estudantes, assim como as competências específicas por área de conhecimento e componente curricular, consoantes com as competências gerais. No tocante a temática da proposta interventiva, ressaltamos a competência geral de número cinco: Cultura Digital. Essa competência determina que os professores planejem suas aulas para que os estudantes possam:

Compreender, utilizar e criar tecnologias digitais de informação e comunicação de forma crítica, significativa, reflexiva e ética nas diversas práticas sociais (incluindo as escolares) para se comunicar, acessar e disseminar informações, produzir conhecimentos, 
resolver problemas e exercer protagonismo e autoria na vida pessoal e coletiva (BRASIL, 2017, p. 9).

Além disso, a BNCC indica que as aprendizagens tidas como essenciais devem contemplar práticas de linguagens contemporâneas, sobretudo, advindas do aperfeiçoamento das tecnologias digitais "[...] como forma de ampliar as possibilidades de participação na cultura digital e contemplar os novos e os multiletramentos" (BRASIL, 2017, p.70). Nessa concepção, as práticas de leitura e de escrita devem inter-relacionar-se com práticas de uso e reflexão sobre as condições de produção e recepção dos textos de tal forma que o professor proporcione os meios para que o estudante seja capaz de:

Analisar as diferentes formas de manifestação da compreensão ativa (réplica ativa) dos textos que circulam nas redes sociais, blogs/microblog, sites e afins e os gêneros que conformam essas práticas de linguagem, como: comentário, carta de leitor, post em rede social, gif, meme, fanfic, vlogs variados, political remix, charge digital, paródias de diferentes tipos, vídeos-minuto, e-zine, fanzine, fanvídeo, vidding, gameplay, walkthrough, detonado, machinima, trailer honesto, playlists comentadas de diferentes tipos etc., de forma a ampliar a compreensão de textos que pertencem a esses gêneros e a possibilitar uma participação mais qualificada do ponto de vista ético, estético e político nas práticas de linguagem da cultura digital (BRASIL, 2017, p.71).

Ainda no que preconiza o referido documento, o processo de alfabetização deve ocorrer nos dois primeiros anos do Ensino Fundamental e inclui como meta proporcionar condições de inserção dos estudantes na cultura digital, cabendo a escola não se abster dessas experiências. Desse modo, o fazer pedagógico deve "mobilizar práticas da cultura digital, por meio da utilização de diferentes linguagens, mídias e ferramentas digitais com o intuito de aprender e refletir sobre o mundo e realizar diferentes projetos autorais" (BRASIL, 2017, p. 87).

Importante demarcar que, como política pública de um país tão diverso cultural e economicamente, a BNCC, ao instituir a homogeneização de competências e habilidades, tendo como o horizonte e justificativa os direitos de aprendizagem de estudantes brasileiros, nos parece trazer uma visão ingênua ou perversa das diferenças que habitam o país. Do mesmo modo, a definição dos currículos de modo uniforme prejudica a autonomia docente e desfavorece processos autorais de produção de saberes. Por outro lado, ponderamos, mesmo com reservas, que o debate que a BNCC provoca a respeito 
das práticas de letramento digital na alfabetização são necessários. Não cabe mais ignorar a cultura digital e suas influências no âmbito da alfabetização e a escola não pode mais se abster de compreender esse fenômeno e potencializar novas práticas alfabetizadoras.

Dessa maneira, com um olhar crítico e situado sob diferentes referenciais, confirmamos a necessidade de a formação do docente alfabetizador se pautar, também, na perspectiva dos multiletramentos a fim de ampliar a compreensão de que o conhecimento sobre a aquisição da língua escrita e falada, nas práticas digitais, não se configura como elemento estranho ao ensino escolar, mas potencializador de cooperação, colaboração e construção de saberes. Além disso, se desenvolvida em uma lógica horizontalizada de rede, a formação tende a se configurar como um importante instrumento para construção de relações sociais e de poder menos desiguais, que favoreça a autoria e que não torne o professor um mero reprodutor de plataformas ou bases curriculares pré-definidas e homogeneizantes. Foi seguindo a essas reflexões que nos sentimos motivadas a contribuir com a criação de novas propostas de formação docente na perspectiva da cultura digital e seus multiletramentos, a partir da elaboração de um Projeto de Intervenção. A seguir, apresentamos o itinerário de pesquisa que deu subsídio para a elaboração da proposta, assim como detalhamos as etapas da intervenção, em si.

\section{A proposta de formação docente em práticas de letramento digital}

Como já anunciado, o Projeto de Intervenção é uma proposta de formação docente em alfabetização na perspectiva dos multiletramentos, mais especificamente, o letramento digital, que tem um cunho investigativo e de rede e possui como ambiente virtual de aprendizagem (AVA), o blog.

O AVA, como são conhecidas as plataformas digitais utilizadas por instituições educativas e empresas para responder a uma demanda educacional de formação e aperfeiçoamento profissional (MESSA, 2010), são espaços on-line de ensino e de aprendizagem. Utilizados na educação presencial e na educação à distância, possuem características colaborativas, abertas e intuitivas, além de serem estruturados de forma flexível, com atividades assíncronas e síncronas e agregando ferramentas digitais com a finalidade de potencializar a produção e difusão do conhecimento.

Nessa perspectiva, propomos o blog - ciberdiários, webdiários ou weblogs - para ser o AVA que mediará a formação para os professores alfabetizadores da rede municipal de Lauro de Freitas, Bahia. A escolha pelo blog se 
deu por ser uma das "[...] práticas contemporâneas de escrita on-line, onde usuários comuns escrevem sobre suas vidas privadas, sobre suas áreas de interesse ou sobre aspectos da cultura contemporânea" (LEMOS, 2010, p. 3). Também, porque o blog se inscreve na perspectiva da formação na rede e em rede e favorece a autoria docente. Além disso,

aos blogs podem ser agregadas outras ferramentas e, o mais importante, relacionar outras pessoas no ambiente e nos processos realizados nele, construindo uma blogosfera cada vez maior, fazendo deste um fenômeno social, onde fica em evidência a criatividade humana (HALMANN, 2006, p. 30, grifos da autora).

Uma das grandes vantagens de trabalhar com o blog está na praticidade da linguagem digital e por não depender de nenhum conhecimento especializado de programação para que seja produzido. Pereira, Schimitt e Dias (2007, p. 9) apontam em seus estudos que "[...] a educação baseada na web está incentivando a utilização desses ambientes virtuais como apoio ao ensino presencial e como modalidade única de ensino e de aprendizagem" e, levando em consideração o contexto da rede de educação pesquisada, nos pareceu o meio mais apropriado para potencializar uma formação em uma perspectiva de investigação e ação em rede.

\subsection{Horizonte metodológico}

É importante apontar que para definirmos que o blog serviria como AVA e quais os percursos em que ele seria agregado na proposta de formação, realizamos anteriormente uma pesquisa exploratória, de cunho qualitativo. A escolha por essa abordagem se deu devido à necessidade de conceber instrumentos de pesquisa adequados ao contexto e aos sujeitos da investigação (GIL, 2002), além da maior atenção que ela fornece à natureza interpretativa da pesquisa, situando o estudo dentro do contexto político, social e cultural dos sujeitos pesquisados e a reflexão contínua dos pesquisadores nas informações registradas (CRESWELL, 2014).

A fim de contemplar o maior número possível de docentes alfabetizadores da rede municipal de educação, a pesquisa foi desenvolvida no âmbito do Programa Mais Alfabetização (PMALFA), oferecido pelo Governo Federal, em parceria com a Prefeitura Municipal de Lauro de Freitas-Ba e envolveu 187 regentes das turmas do ciclo de alfabetização 1 , 2으 e 3을 anos do Ensino Fun- 
damental ${ }^{7}$. Como instrumento de coleta de dados, utilizamos um questionário on-line, distribuído no período de 10 de julho à 10 de agosto de 2019, com uma questão aberta e doze perguntas de múltipla escolha que, no âmbito dos objetivos do Projeto de Intervenção, visavam a identificar como os professores concebiam as práticas alfabetizadoras na perspectiva dos multiletramentos e as suas competências e habilidades em termos de letramento digital.

De acordo com as respostas, podemos afirmar que os professores concebem a importância da alfabetização na perspectiva dos multiletramentos, porém não possuem elementos práxicos suficientes para potencializarem o letramento digital. $\mathrm{Na}$ análise dos dados, buscamos compilar informações sobre à utilização de ferramentas digitais para implementar estratégias pedagógicas. Nesta dimensão, dos 187 respondentes, 132 professores afirmaram ter encontrado alguma dificuldade em propor novas metodologias com o uso das tecnologias digitais por não saberem operar os equipamentos para esta finalidade, inclusive, o próprio telefone celular. No que tange a elaboração de atividades de aprendizagem que implicam a criação de conteúdos digitais, como vídeos, áudio, fotos, apresentações digitais, blogs, wikis, 157 docentes afirmaram ter encontrado alguma dificuldade para concluir as ações dessa natureza, sendo que destes, 55 responderam que não possuíam equipamento adequado para elaboração de aulas e criação de material didático. Do total de respondentes, apenas 30 professores afirmaram não ter encontrado nenhuma dificuldade na utilização das tecnologias digitais em suas aulas.

Os dados levantados indicaram que cerca de 70,5\% dos professores não conseguem planejar ou executar aulas que envolvem a utilização de tecnologias digitais, por não terem familiaridade com as mesmas. Cerca de $13,5 \%$ afirmam saber fazer uso das ferramentas, mas indicaram falta de acesso aos equipamentos e $16 \%$ afirmaram não possuir dificuldades com o uso das tecnologias digitais em sala de aula. Desse modo, $84 \%$ dos professores alfabetizadores da Rede Municipal de Educação de Lauro de Freitas-Ba não conseguem planejar ou executar aulas que envolvem a utilização de tecnologias digitais, por não terem familiaridade com as mesmas ou por não possuírem um equipamento adequado à criação de conteúdo digital, o que demonstra um descompasso entre as necessidades formativas dos sujeitos na sociedade contemporânea e a qualificação docente para potencializar tais aprendizagens nos estudantes.

A realidade apontada pela pesquisa nos provocou algumas reflexões: Como os docentes da rede poderão favorecer um processo de alfabetização

\footnotetext{
${ }^{7}$ Recebemos as respostas de todos os questionários. Acreditamos que um fator preponderante para o envio de $100 \%$ das respostas foi a vinculação dos docentes ao PMALFA.
} 
que inclua o letramento digital, se a maior parte deles não está imersa neste contexto, em termos pedagógicos? Como a rede de educação pode se corresponsabilizar por esta realidade? De que modo uma proposta formativa poderá delinear proposições dessa natureza, levando em consideração a realidade da rede e os saberes que os docentes já possuem? A partir desses questionamentos buscamos propor uma formação que, em uma perspectiva de investigação e ação em rede, potencializasse a autoria docente no âmbito do letramento digital.

Como os resultados da pesquisa exploratória indicaram que a maioria dos professores não possui familiaridade com as tecnologias digitais, encontramos no blog, devido à sua natureza intuitiva e bastante acessível, um meio introdutório para a imersão deles em práticas de alfabetização via letramento digital, além de favorecer a colaboratividade e a autonomia para criarem redes formativas. Assim, a proposta se baseia em um propósito de duas chaves: 1. Uma formação em exercício, por meio de investigação e ação em rede, na qual os professores vivenciarão aprendizagens de letramento digital, abarcando linguagens multimodais e hipermidiáticas, que potencializem reflexões sobre a prática pedagógica e a produção de recursos educacionais digitais; 2 . A paulatina implementação dessas práticas em suas aulas, potencializando o letramento digital de seus alunos.

\subsection{A proposta interventiva}

Como exposto, diante dos dados levantados ficou evidente a necessidade de construirmos uma proposta de formação teórico-prática que favorecesse a autoria docente, estivesse voltada para a vivência de letramento digital e situada em posturas de investigação e ação para a rede, na rede e em rede (ALMEIDA, 2010). Desse modo, inspiradas nos estudos de Tripp (2005) sobre pesquisa-ação, delineamos eixos que subsidiaram a elaboração da proposta interventiva. Para Tripp (2005, p. 445) a pesquisa-ação pode ser concebida como "[...] uma estratégia para o desenvolvimento de pesquisadores e professores de modo que eles possam utilizar suas pesquisas para aprimorar seu ensino e, em decorrência, o aprendizado de seus alunos". Pretende-se, assim, que a formação oferte subsídios para que os professores coletem informações que contribuíam com a compreensão dos problemas encontrados em suas salas de aula, tomem decisões e modifiquem as ações em sua práxis pedagógica, ou seja, que sigam

[...] um ciclo no qual se aprimora a prática pela oscilação siste- 
mática entre agir no campo da prática e investigar a respeito dela. Planeja-se, implementa-se, descreve-se e avalia-se uma mudança para a melhora de sua prática, aprendendo mais, no correr do processo, tanto a respeito da prática quanto da própria investigação (TRIPP, 2005, p. 445-446).

Assim, delineamos a proposta formativa a partir de dois eixos, interligados e que não possuem caráter hierárquico ou de sobreposição: 1. Mudança da prática - através do acompanhamento da organização do trabalho pedagógico, por meio da elaboração de recursos educacionais e da construção e execução de uma rotina didática, com sequências e projetos pedagógicos em práticas letradas digitais; 2 . Investigação e produção de conhecimento profissional - para que a formação não seja meramente técnica e que a autoria docente, a partir da postura investigativa, seja favorecida.

O eixo de mudança da prática é denominado por Tripp (2005) como a fase da ação, entendida de modo ampliado, pois envolve, também, o planejamento e a avaliação das implicações geradas pela ação. $O$ eixo de investigação e produção de conhecimento profissional é o momento em que os docentes devem projetar e implementar ações de pesquisa da prática, envolvendo a análise dos dados e a reorientação da ação. Vale ressaltar que, como se trata de um ciclo de investigação e ação, os dois eixos são comunicantes e interdependentes.

Com tais indicativos Tripp (2005) relaciona a pesquisa-ação educacional a duas dimensões recíprocas: uma ligada ao trabalho em sala de aula, através do planejamento e da avaliação das necessidades e expectativas dos estudantes em relação ao trabalho pedagógico, tendo em vista à sua melhoria; e a outra, como envolve um esteio investigativo, podemos inferir que está ligada a formação visando, também, a melhoria da prática pedagógica.

Outra característica do relacionamento recíproco entre pesquisa e prática aprimorada é que não apenas se compreende a prática de modo a melhorá-la na pesquisa-ação, mas também se ganhe uma melhor compreensão da prática rotineira por meio de sua melhora, de modo que a melhora é o contexto, o meio e a finalidade principal da compreensão (TRIPP, 2005, p. 450).

Relacionando os eixos e as dimensões da pesquisa-ação, conforme proposta por Tripp (2005), aos princípios teóricos que alicerçaram o Projeto de Intervenção, delineamos um intercruzamento entre a instituição de posturas 
de investigação e ação com a formação para a rede, na rede e em rede. Esse intercruzamento foi sistematizado na proposta interventiva e sintetizado no quadro a seguir:

Quadro 1: Proposta de formação docente em alfabetização e multiletramentos

\begin{tabular}{|c|c|c|}
\hline Eixos & & \\
\hline$\frac{.0}{\frac{n}{2}}$ & Mudança da prática & $\begin{array}{l}\text { Investigação e produção } \\
\text { de conhecimento } \\
\text { profissional }\end{array}$ \\
\hline 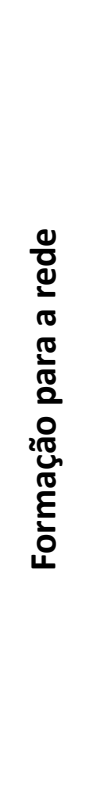 & $\begin{array}{l}\text { - Apresentação da } \\
\text { proposta; } \\
\text { - } \quad \text { Mobilização e } \\
\text { engajamento dos } \\
\text { profissionais na } \\
\text { proposta; } \\
\text { - Análise coletiva dos } \\
\text { dados da pesquisa } \\
\text { e delineamento } \\
\text { colaborativo } \\
\text { da proposta de } \\
\text { formação docente. }\end{array}$ & 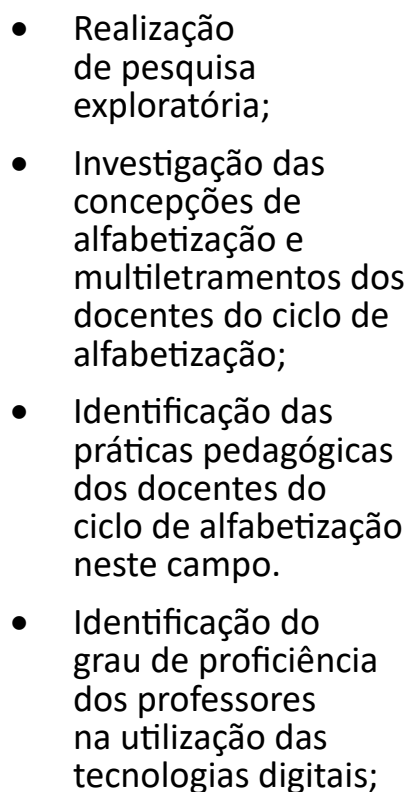 \\
\hline
\end{tabular}




\begin{tabular}{|c|c|c|}
\hline 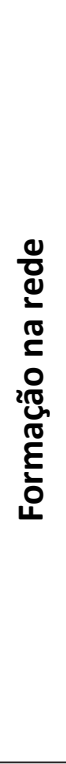 & $\begin{array}{l}\text { - Aproximação dos } \\
\text { docentes com a } \\
\text { natureza dos blogs, } \\
\text { no que se refere à } \\
\text { criação, edição e } \\
\text { disseminação de } \\
\text { conteúdo; } \\
\text { - Oficinas de } \\
\text { produção } \\
\text { de recursos } \\
\text { educacionais } \\
\text { digitais; } \\
\text { - Criação dos blogs; } \\
\text { - Utilização piloto } \\
\text { dos recursos } \\
\text { educacionais } \\
\text { digitais produzidos } \\
\text { nas oficinas; }\end{array}$ & $\begin{array}{l}\text { - Criação de grupos } \\
\text { de estudos } \\
\text { semipresenciais } \\
\text { sobre Pedagogia } \\
\text { na perspectiva da } \\
\text { Alfabetização e } \\
\text { Multiletramentos e } \\
\text { letramento digital; } \\
\text { - } \quad \text { Diagnóstico inicial } \\
\text { da atividade piloto } \\
\text { de utilização } \\
\text { dos recursos } \\
\text { educacionais digitais; } \\
\text { Avaliação da } \\
\text { proposta com base } \\
\text { no diagnóstico. }\end{array}$ \\
\hline 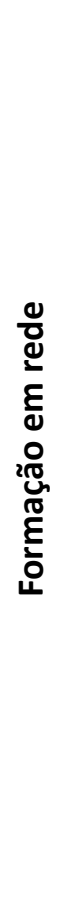 & $\begin{array}{l}\text { - Elaboração de } \\
\text { planos, sequências } \\
\text { e materiais } \\
\text { didáticos tendo o } \\
\text { letramento digital } \\
\text { como um dos } \\
\text { horizontes práxicos; } \\
\text { - Instituição de } \\
\text { práticas de } \\
\text { letramento digital } \\
\text { nas aulas dos } \\
\text { professores do ciclo } \\
\text { de alfabetização; } \\
\text { Planejamento } \\
\text { de intervenções } \\
\text { para superar } \\
\text { as dificuldades } \\
\text { encontradas pelos } \\
\text { docentes; } \\
\text { Avaliação } \\
\text { continuada dos } \\
\text { processos. }\end{array}$ & $\begin{array}{l}\text { - Levantamento } \\
\text { de dados para } \\
\text { a identificação } \\
\text { das dificuldades } \\
\text { encontradas pelos } \\
\text { professores com as } \\
\text { práticas voltadas } \\
\text { para o letramento } \\
\text { digital; } \\
\text { - Compartilhamento } \\
\text { dos dados e análise } \\
\text { coletiva; } \\
\text { - Utilização dos blogs } \\
\text { como ambiente de } \\
\text { aprendizagem virtual } \\
\text { e portfólio digital; } \\
\text { Divulgação dos blogs } \\
\text { e articulação de } \\
\text { redes formativas. }\end{array}$ \\
\hline
\end{tabular}

Fonte: Produção das autoras 
A proposta indica que os docentes têm autonomia para produzir o blog individual ou coletivamente. Seja qual for a escolha dos professores é importante ressaltar que o link com o endereço dos ambientes ficará ativo e disponível no site da escola e no portal da secretaria de educação, a fim de favorecer a criação de uma blogosfera. O PI também prevê o prazo de um ano letivo para que os processos de estudo, pesquisa, elaboração de instrumentos e materiais pedagógicos tenham sido amadurecidos e para que os blogs possam começar a se configurar como redes formativas. A ideia é que as práticas de alfabetização e letramento em perspectivas digitais sejam acessíveis a todos os professores da rede municipal de educação de Lauro de Freitas-Ba, podendo ser extensivas para outros espaços, pois entendemos que

[...] construir redes nas escolas é de fundamental importância, visto que são essas que, além de mexer com as estruturas internas, podem colocar cada escola numa rede social mais ampla, de modo que a diversidade própria de cada contexto educativo seja fortalecida (BONILLA, 2009, p. 37).

É nesse prisma que se insere a noção de formação em redes de aprendizado desenvolvida na proposta de intervenção, aqui, apresentada. Ao proporcionar espaços de produção colaborativa como o blog acreditamos que os professores se relacionem em torno de um interesse comum, se inspirem mutuamente, problematizem suas práticas no coletivo e compreendam que o letramento digital é um horizonte epistemológico necessário às relações de ensino e de aprendizagem na contemporaneidade e que o ensino da alfabetização não pode estar dissociado desse âmbito.

\section{Considerações finais}

O amplo acesso à informação e à comunicação, por meio das tecnologias digitais, tem reconfigurado os processos de ensino e de aprendizagem, apontando para a necessidade de ressignificar saberes e práticas docentes com o intuito promover uma educação consoante com as necessidades do educando na contemporaneidade.

No âmbito das práticas de alfabetização e de letramento, estudos sobre os multiletramentos, por exemplo, vêm alargando o horizonte formativo dos professores, no sentido ampliar a atenção dos aspectos instrucionais da língua, incluindo também, aspectos da cultura digital. Nesse contexto, inscrevem-se questões inerentes à formação em exercício de professores, conceben- 
do-os como atores e autores de seu processo formativo, instituindo práticas de reflexão e de pesquisa da própria prática, em perspectivas colaborativas e de rede, para a construção de habilidades e competências ligadas a utilização, produção e difusão de conteúdo digital nos mais diversos formatos, a fim de essa dimensão ressoe na aprendizagem dos alunos.

Foi pensando nessas perspectivas que o Projeto de Intervenção foi delineado. A proposta interventiva foi iniciada a partir da pesquisa exploratória que favoreceu a realização de um diagnóstico da realidade dos docentes alfabetizadores da Rede Municipal de Lauro de Freitas-Ba. Com estes dados emergiu a necessidade de formação em serviço e, diante do esteio teórico sobre formação docente na cultura digital e sobre alfabetização e multiletramentos, concebemos a importância de criar uma proposta colaborativa, que favorecesse a autoria docente, através de práticas de investigação e ação em rede, tendo como inspiração os estudos de Tripp (2005) sobre pesquisa-ação e de Almeida (2010) sobre formação em redes.

Vale registrar que Projeto de Intervenção concluiu a fase de formação para a rede e se encontra na fase de formação na rede, quando se iniciará a criação dos blogs, servindo não apenas para a apropriação de estratégias de letramento digital, mas, também, como potencializadores de redes formativas com viés investigativo ${ }^{8}$. Todas as etapas preveem momentos de avaliação e a partir da fase de formação em rede colheremos elementos das investigações práxicas desenvolvidas pelos docentes, quando será possível conceber, de modo substancial, os impactos da intervenção na realidade educacional da referida rede educativa. Dessa forma, acreditamos que estamos contribuindo para que as escolas se tornem, também, um espaço colaborativo de desenvolvimento profissional, através da reflexão-investigação-ação do trabalho pedagógico para que essa dimensão ressoe nas aprendizagens dos alunos das classes de alfabetização.

\section{REFERÊNCIAS}

ALARCÃO. Isabel. Professores reflexivos em uma escola reflexiva. São Paulo: Cortez, 2010.

ALMEIDA, Verônica Domingues; SÁ, Maria Roseli Gomes Brito de. Concepções de intervenção do Mestrado Profissional em Educação: tessituras curriculares de uma pesquisa. In: 38a Reunião Nacional da ANPEd, 2017, São Luís: UFMA.

\footnotetext{
${ }^{8}$ Vale ressaltar que o cronograma inicial teve o prazo impactado pela pandemia de Covid-19, que assolou o mundo ao final do ano de 2019 se estendendo por todo o ano de 2020.
} 
Disponível em: http://anais.anped.org.br/sites/default/files/arquivos/trabaIho_38anped_2017_GT12_1323.pdf Acesso em: 03 fev. 2020.

ALMEIDA, Verônica Domingues. Formação em redes e redes de formação: Trajetórias de professores e a rede web como processo e possibilidade. In: Presente! Revista de Educação. Centro de Estudos e Assessoria Pedagógica, Ano 19, n. 01, v. 67, abr. 2010, p. 38-46.

BONILLA, Maria Helena. Escola aprendente: desafios e possibilidades postos no contexto da sociedade do conhecimento. 2002. Tese (Doutorado) - Universidade Federal da Bahia, Faculdade de Educação, 2002.

BONILLA, Maria Helena. A práxis pedagógica presente e futura e os conceitos de verdade e realidade frente às crises do conhecimento científico no século XX. In: Tecnologia e novas educações. Salvador: EDUFBA, 2005, p. 71- 80.

BONILLA, Maria Helena. Escola aprendente: comunidade em fluxo. In: FREITAS, Maria Teresa de Assunção (org.). Cibercultura e formação de professores. Belo Horizonte: Autêntica, 2009, p. 23-40.

BRASIL. Pacto Nacional pela Alfabetização na Idade Certa: Currículo na alfabetização: concepções e princípios. Brasília: MEC/Secretaria de Educação Básica, Diretoria de Apoio à Gestão Educacional, 2012. Disponível em: https://www. pomerode.sc.gov.br/arquivos/SED/ano1/unidade_01_ano_01(07_11_2012). pdf

BRASIL. Base Nacional Comum Curricular: Educação Infantil e Ensino Fundamental. Brasília: MEC/Secretaria de Educação Básica, 2017. Disponível em: http://basenacionalcomum.mec.gov.br/images/BNCC_EI_EF_110518_versaofinal_site.pdf

CRESWELL, John. Investigação qualitativa e projeto de pesquisa: escolhendo entre cinco abordagens. 3. ed. Porto Alegre: Penso, 2014.

FREIRE, Paulo. A pedagogia do oprimido. 59. ed. Rio de Janeiro: Paz e Terra, 2015.

FREITAS, Maria Teresa. A formação de professores diante dos desafios da cibercultura. In: FREITAS, Maria Teresa. (Org.). Cibercultura e Formação de professores. 01. ed. Belo Horizonte: Autêntica Editora, 2009.

GIL, Antônio Carlos. Como Elaborar Projetos de Pesquisa. 4. ed. São Paulo: Atlas, 2002.

HALMANN, Adriane Lizbehd. Reflexões de professores em blogs: aspectos e 
possibilidades. Dissertação (Mestrado). Universidade Federal da Bahia, Faculdade de Educação, 2002.

KENSKI, Vani. Tecnologias e ensino presencial e a distância. Campinas, São Paulo: Papirus, 2003.

ALBUQUERQUE, Eliana B. C. de; MORAIS, Artur G. de; FERREIRA, Andréa Tereza B. (org.). A relação entre alfabetização e letramento na educação de jovens e adultos: questões conceituais e seus reflexos nas práticas de ensino e nos livros didáticos. In: FERRAZ, Telma; ALBUQUERQUE, Eliana B. C. de; MORAIS, Artur G. de. Alfabetizar letrando na EJA: fundamentos teóricos e propostas didáticas. Belo Horizonte: Autêntica Editora, 2010.

LEMOS, André. Cibercultura: tecnologia e vida social na cultura contemporânea. 5. Ed. Porto Alegre: Sulina, 2010.

LÉVY, Pierre. Uma perspectiva vitalista sobre a cibercultura. In: LEMOS, André. Cibercultura: tecnologia e vida social na cultura contemporânea. 5. Ed. Porto Alegre: Sulina, 2010.

MESSA, Wilmara Cruz.Utilização de ambientesvirtuais deaprendizagem-AVAs: a busca por uma aprendizagem significativa. In: Revista Brasileira de Aprendizagem Aberta e a Distância, v. 9, 2010, p. 1-46. Disponível em:http://www. abed.org.br/revistacientifica/Revista_PDF_Doc/2010/2010_2462010174147. pdf. Acesso em 11 abr. 2018.

PRETTO, Nelson De Luca; ASSIS. Alessandra. Cultura digital e educação: redes já! In: PRETTO, Nelson De Luca; SILVEIRA, Sérgio Amadeu da (Org.). Além das redes de colaboração: internet, diversidade cultural e tecnologias do poder. Salvador: EDUFBA, 2008. 232 p.

NÓVOA, Antônio. Formação de professores e profissão docente. In. NÓVOA, Antônio. (org.) Os Professores e sua formação. Lisboa: Dom Quixote, 1992.

PEREIRA, Alice Theresinha Cybis; SCHMITT, Valdenise; DIAS, Maria Regina Álvares Correia. Ambientes Virtuais de Aprendizagem. In: PEREIRA, Alice. Theresinha Cybis. (Org.). Ambientes Virtuais de Aprendizagem em Diferentes Contextos. Rio de Janeiro: Ciência Moderna, 2007, p. 2-22. Disponível em: http://www.pucrs.br/ciencias/viali/tic_literatura/artigos/ava/2259532.pdf Acesso em: 11 abr. 2018.

ROJO, Roxane; MOURA, Eduardo. In: Multiletramentos na escola. São Paulo: Parábola, 2012.

SANTOS, Edmea. A mobilidade cibercultural: cotidianos na interface educa- 
ção e comunicação. In: Em Aberto, v. 28, n. 94, 2015. Disponível em: http:// rbep.inep.gov.br/ojs3/index.php/emaberto/article/view/3059 Acesso em: 13 nov. 2019.

SOARES, Magda. Letramento: um tema em três gêneros. Belo Horizonte: Autêntica, 1998.

SOARES, Magda. Novas práticas de leitura e escrita: letramento na cibercultura. In: Educação e Sociedade, Campinas, v.23, n.81, p.143-160, dez. 2002. Disponível em: http://www.scielo.br/scielo.php?script=sci_arttext\&pid=S0101-73302002008100008\&lng=en\&nrm=iso Acesso em: 11 jan. 2020.

TRIPP, David. Pesquisa-ação: uma introdução metodológica. In: Educação e Pesquisa, São Paulo, v. 31, n. 3, p. 443-466, set./dez. 2005. Disponível em: http://www.scielo.br/pdf/ep/v31n3/a09v31n3.pdf. Acesso em: 25 jun. 2019.

Data de recebimento: 07.07.2020

Data de aceite: 26.12.2020 